\title{
Recent Survey of Automated Rehabilitation Systems Using EMG Biosensors
}

\author{
NiZAM UdDin AHAMED, MSc ${ }^{1)}$, KENNETH SUndARAJ, PhD ${ }^{2)}$, R BADliSHAH AHMAD, PhD ${ }^{3)}$, \\ SivadeV NADARAJAH, MSc ${ }^{2}$, PoO TARn Shi, MSc ${ }^{2}$, SAM MATIUR RAHMAN ${ }^{4}$ \\ ${ }^{1)}$ School of Computer Engineering, Universiti Malaysia Perlis: No.12 \&14, Jalan Satu, Taman Seberang \\ Jaya Fasa 3, 02000 Kuala Perlis, Kangar, Perlis, Malaysia. \\ TEL:+60 162727065,E-mail: ahamed1557@hotmail.com. \\ ${ }^{2)}$ School of Mechatronic Engineering, Universiti Malaysia Perlis \\ ${ }^{3}$ School of Computer and Communication Engineering, Universiti Malaysia Perlis \\ 4) College of Computer Science and Information System, Najran University
}

\begin{abstract}
Purpose] In this paper, we present a survey of some recently developed techniques in the field of automatic rehabilitation systems assisted by electromyography (EMG) biosensors and their application in physically disabled patients. We also include a discussion about the implementation of several hardware and software models for rehabilitation to make the full process dynamics. [Methods] A systematic search for articles published from 2000 to March 2011 was conducted in the IEEE, Springer Link, Pub Med and ACM digital library databases. The search plan was developed using different terms referring to rehabilitation, EMG sensors and automatic systems as well as we used number of keywords related to the subject of our survey along with their synonyms. The entire survey was performed in the automatic rehabilitation lab (Biomedical Engineering) of the Universiti Malaysia Perils (UniMAP) from December 2010 to March 2011. [Result] A total of 22 articles were analyzed in our study. Of these, 17 articles were about EMG-aided recovery systems developed for the impaired human body. Finally, we confirmed that all of the EMG-supported rehabilitation systems are noninvasive, assisted by a computer or robot and most of them are real-time processes. [Conclusion] Obviously, it is difficult to complete a survey within a single article of all possible EMG- generated rehabilitation systems. However, we expect that the references cited will cover the main theoretical and practical issues, guiding the researcher in interesting research and suggesting promising EMG-aided rehabilitation techniques that have yet to be explored.
\end{abstract}

Key words: EMG, Rehabilitation, Biosensor

(This article was submitted May 11, 2011, and was accepted Jul. 13, 2011)

\section{INTRODUCTION}

A disable patient's physical condition can recover after receiving proper treatment using an appropriate and easy to use automated medical rehabilitation system, and thus the patient's physical condition can return to an earlier stage. The entire process plays a vital role after a severe accident, major operation, unexpected ailment, chronic pain, orthopedic anarchy, brain injury, Parkinson's disease (a disorder of the central nervous system) and psychological anarchy (drug addicted or shocked people) and may be needed for older individuals. Cardiopulmonary, neurological, orthopedic, pediatric and integumentary (skin and related organ) disorders are the most important and common areas in the human body that need rehabilitation systems.

In biomedical engineering, physiological sensors are one of the fundamental part for biosignal processing and automatic medical rehabilitation method. More precisely, biosignals offer novel communication and control channels between humans and machines or, specifically, between the pinion sufferer and the computer/robot in rehabilitation engineering ${ }^{5)}$. The electromyography (EMG) biosensor is one of the primary assistive components of disable patient's automatic recovery systems and has many important benefits for neuromuscular disorders, such as the ability to isolate the muscles needed to move the device without the interactions of the adjoining muscles. Moreover, it can detect the active participation of a patient and use this information to both decrease or increase assistance and resistance as appropriate to extend the progress towards the subject. The main reason why this is possible is that the EMG signal can carry important information about the nervous system, and thus, it has a wide application in the field of neuromuscular human physiology, biometrics, physical healing (in case of improper muscle movements) and postural control ${ }^{2-4)}$. Furthermore, EMG can assess electrical movement of muscle and produce a signal of the patient's aim to move a limb ${ }^{5}$; as a result, this indicator helps patients in their rehabilitation.

To date, many researchers have surveyed automatic rehabilitation systems with different processes. However, we could not find any previous reported work that summarized and combined rehabilitation systems in regard to EMG biosensors, hardware and software. We found one study by Majdalawieh et al. (2003) that presented and reviewed only 
the relation between biomedical signals and rehabilitation engineering with EMG, EEG, neural networks, wavelet transforms and Fourier transforms ${ }^{6}$. However, we tried to fill in this blank in the present survey paper.

Our review paper is organized as follows. In Methods section, we described the different keywords used in our search, listed the online database names and reported the time frame to obtain the desired outcome. In the Results section, we summarized all the EMG-assisted automated rehabilitation systems according to the applicable damage to the human body. Furthermore, a number of usable pieces of hardware and software are presented here. This section also includes some limitations highlighted during development of the systems. The next section constructs an overall discussion for developing new rehabilitation systems aided by EMG. The Conclusion follows this section, where we discussed some positive sides to develop of the rehabilitation systems. Also, we focused on our future work for automatic recovery prosess with EMG sensors in a new area of the human body.

\section{METHODS}

A methodical search of articles from 2000 to March 2011 was conducted in the following online databases: IEEE, Springer Link, PubMed and ACM digital library. The criteria for relevance in the article search mainly focused on EMG sensor-supported automated rehabilitation systems in different types of human body impairment. This literature search was carried out from December 2010 to March 2011 in Universiti Malaysia Perlis (UniMAP) rehabilitation (Biomedical Engineering) lab. All the important information in the published articles from 2000 to 2011 was reviewed. The recovery systems developed within this period are listed in Table 1. Only papers published in English in preferred international journals and conference proceedings were considered for the study.

We used key words like rehabilitation, automated, system and EMG sensor and also inserted some synonyms to obtain more and deeper results for the study. Furthermore, boolean operators like AND, OR, and NOT were used in searches to obtain the desired information. Only complete papers are included in our review. Abstracts published as conference, workshop or symposium proceedings were not considered, as the information presented was insufficient to allow for detailed analysis in the present work.

\section{RESULTS}

\section{Developed rehabilitation systems}

Currently, the main intentions and needs for automated rehabilitation technology are for devices that are very comfortable, will show correct and prompt results, are lucrative, are real-time process and are easy to operate. Moreover, devices should reduce the massive burden of the caregivers and psychotherapists. In Table 1, we have listed all the EMG biosensor-assisted automated rehabilitation systems and the application area of the human body.

\section{Assistive technology}

From our survey, we identified two types of assistive technology for rehabilitation, the computer and the robot. The computer-assisted rehabilitation system is much less labor intensive as compared with other conventional manually assisted movements applied by therapists. Hardware and software are the fundamental elements and bridge of communication for computerized rehabilitation technology. In our review process, we found different types of hardware and software technology, and their names are listed in Table 1.

The implementation of sensor-assisted robots in automated rehabilitation technology is often associated with assistive devices, such as some used in professional environments and some used as aids to daily living or more specifically as feeding devices. Prosthetics and orthoses are the two major basic components in rehabilitation robotics. A prosthesis is an artificial limb, although it can also be for an internal organ or joint. On the other hand, an orthosis is a device that supports or controls part of the body ${ }^{20}$.

\section{Limitations when using EMG Sensors}

A few researchers faced some restrictions during development of their rehabilitation systems with EMG sensors. We presented whatever the authors claimed and describe the problems they faced during development. We found five articles in which the authors pointed out some limitations, dissatisfaction and difficulties in setting up their rehabilitation mechanisms.

To begin with, Andreasen et al.(2005) proposed three prototypes for poststroke rehabilitation with EMG sensors, but the first and second prototypes were too complicated to be practical ${ }^{11)}$. Mulas's et al. (2005) reported a rehabilitation process that end users do not use on their own and that can be used in more advanced phases of therapy. Initially, the device shows result very slowly in their model, but no EMG signals were recorded ${ }^{8)}$. Son et al.(2007) suggested EMG generated study of a rehabilitation system for hemiplegic patients, but basic clinical testing was not performed in the study, and the experimental orthosis subsequently bent ${ }^{12)}$. Jaehoon et al. (2007) expressed a desire to further improve their technique after not obtaining exact results from their proposed EMG pattern recognition method for lower limb balance recovery ${ }^{1)}$. Homma et al. (2003) introduced wire drove mechanisms for a leg rehabilitation system, and in their proposed structure, they found that the obtained motion range was smaller than the target motion range by $20 \%$ when compared with a different method. Afterward, they determined that the reason for this is subject position errors ${ }^{15)}$.

\section{DISCUSSION}

We strongly believe that this is the first report of a survey of EMG-assisted rehabilitation systems combined with hardware and software technology. Because, our systematic review attempted to answer the question, "What are the most recent EMG-assisted automated rehabilitation systems developed for the damaged human body?" from the beginning, we tried to gather the as many of the latest 
Table 1. An overview of EMG sensors -assisted automatic rehabilitation systems

\begin{tabular}{|c|c|c|c|c|c|}
\hline Author & $\begin{array}{l}\text { System s } \\
\text { assisted by }\end{array}$ & $\begin{array}{l}\text { Rehabilitation } \\
\text { Area }\end{array}$ & $\begin{array}{l}\text { Real time } \\
\text { (Yes/No) }\end{array}$ & Software used/proposed & Hardware used/proposed \\
\hline Mulas et al. ${ }^{8}$ ) & Computer & Hand (finger) & Yes & C, MATLAB & A circuit board, PC, microcontroller \\
\hline Qingling et al. ${ }^{9)}$ & Robot & Upper limb & $\begin{array}{l}\text { No, } \\
\text { method }\end{array}$ & GUI running on Windows 2000 & $\begin{array}{l}\text { ADLINK DAQ, Intel P4 } 2.4 \mathrm{GHz} \\
\text { system }\end{array}$ \\
\hline Kiguchi et al. ${ }^{10)}$ & Robot & Elbow (arm) & Yes & $\mathrm{NCM}$ & $\begin{array}{l}\text { DC motor, a ball screw drive shaft and } \\
\text { support frame, wrist holder, PC }\end{array}$ \\
\hline $\begin{array}{l}\text { Mohammaddan et } \\
\text { al. }{ }^{2)}\end{array}$ & Robot & Finger & Yes & CAD & $\begin{array}{l}\text { Wire driven, flexor cable, DC motor, } \\
\text { mild steel cable, PVC, plastic }\end{array}$ \\
\hline Andreasen et al. ${ }^{11)}$ & Robot & $\begin{array}{l}\text { Brain and } \\
\text { stroke }\end{array}$ & Yes & Windows $\mathrm{XP}, \mathrm{C}++$ & PC or notebook, DAQ card \\
\hline Hokyoo et al. ${ }^{18)}$ & Robot & Upper limb & Yes & $\begin{array}{l}\text { Software for system control, user } \\
\text { interface and haptic device program }\end{array}$ & $\begin{array}{l}\text { PC, a display board, haptic devices, } \\
\text { grip }\end{array}$ \\
\hline Son et al. ${ }^{12)}$ & Robot & Hemiplegic & Yes & $\begin{array}{l}\text { EMG measurement software (Noraxon } \\
\text { U.S.A.), C }\end{array}$ & $\begin{array}{l}\text { Biodex, Motor RE } 40 \text { (Maxon), } \\
\text { microcontroller }\end{array}$ \\
\hline Chih-Fu et al. ${ }^{13)}$ & Computer & Upper limb & Yes & $\begin{array}{l}\text { Visual basic, Windows XP, database } \\
\text { program }\end{array}$ & $\begin{array}{l}\text { PC, PCI counter board, PCI data } \\
\text { acquisition card }\end{array}$ \\
\hline Cano-Garcia et al. ${ }^{19)}$ & $\begin{array}{l}\text { Computer } \\
\text { (PDA) }\end{array}$ & Heart & Yes & $\begin{array}{l}\text { Linux OS, server model: } \mathrm{C} \text { code with } \\
\text { Comedi API, graphical design with } \\
\text { C++ }\end{array}$ & $\begin{array}{l}\text { Bluetooth, DAQ card, PDA, graphical } \\
\text { client application and web page } \\
\text { interface, microcontroller chip, PDAs }\end{array}$ \\
\hline Steinisch et al. ${ }^{14)}$ & Robot & $\begin{array}{l}\text { Stroke } \\
\text { (upper limb) }\end{array}$ & $\begin{array}{l}\text { No } \\
\text { (a project) }\end{array}$ & Virtual reality software (NCM) & $\begin{array}{l}\text { Robot, haptic devices, online } \\
\text { equipments. }\end{array}$ \\
\hline Sangit et al. ${ }^{7)}$ & Computer & $\begin{array}{l}\text { Stroke } \\
\text { (Upper limb } \\
\text { paralysis) }\end{array}$ & Yes & MATLAB software, $C$ program. & $\begin{array}{l}\text { Microcontroller chip (PIC } 24 \text { HJI28), } \\
\text { 16- bit ADC }\end{array}$ \\
\hline Homma et al. ${ }^{1)}$ & Computer & $\begin{array}{l}\text { Leg/lower limb } \\
\text { (hip, ankle) }\end{array}$ & Yes & AC/DC software (NM) & $\begin{array}{l}\text { Rails, wires, bed, a controller, winding } \\
\text { mechanism, PC }\end{array}$ \\
\hline Raichur et al. ${ }^{16)}$ & Robot & Stroke & Yes & Lab view 8.0, windows $\mathrm{XP}$ & Co-processor P4, 5 GB ram, NI-USB \\
\hline Xing et al. ${ }^{17)}$ & Robot & Post stroke & Yes & DAQ software (NCM). & Microcontroller chip, LCD display. \\
\hline Sasidhar et al..$^{5)}$ & Computer & $\begin{array}{l}\text { Stroke(wrist } \\
\text { and elbow) }\end{array}$ & Yes & MATLAB software. & PC, glove, other (NCM) \\
\hline Jeong-Su et al. ${ }^{21)}$ & Robot & Elderly & Yes & MATLAB software & $\mathrm{A} / \mathrm{D}$ converter, $\mathrm{PC}, \mathrm{AD}$ amp \\
\hline Xiao et al. ${ }^{22}$ ) & Robot & Stroke & Yes & DAQ software & Robot-assisted devices \\
\hline
\end{tabular}

$\mathrm{NCM}=$ Not Clearly Mentioned, OS= Operating System, NM=Not Mentioned.

results for rehabilitation systems as possible. We also included some drawbacks about rehabilitation mechanisms so that researchers using the EMG sensors would be aware of them. Finally, the key findings of this study are, described below.

1) We found 17 recovery systems in 22 papers.

2) The targets of the rehabilitation systems were the upper and lower limbs, stroke, the ankles, the shoulders, the fingers, poststroke recovery, chronic pain and the elderly.

3) A noninvasive technique was applied for EMG signal generation because the user feels comfortable with this type of technique.

4) All the rehabilitation systems provided assistance with either a computer or robot.

5) In our survey, we listed the names of a number of different pieces of hardware and software for these real-time systems, such as programming languages, microcontroller chips, operating systems, DAQ cards and software, several PC models, database applications, web technologies, technologies displaying results on PDAs and client-server database technologies. We hope that, these systems will be helpful for the future rehabilitation researcher.

\section{CONCLUSION}

In this article, the current "state of the art" EMG-generated automated rehabilitation processes have been reviewed. We attempted to report all possible results of rehabilitation studies to date. The main application areas of these systems were the wrist, finger, stroke rehabilitation (upper and lower limb), the elderly and functional activity monitoring (progress or retreat) of daily living exercise. A range of journal and conference papers were analyzed to fulfill the objective. Finally, we hope that the EMG sensor can be used to develop some good automated assisted rehabilitation systems for parts of the human body that are 
not covered by current systems because our main goal in performing this systematic analysis was to investigate this gap for the rehabilitation process.

Our team considered that recommendations should be based on strong and clear levels of evidence. A powerful level of proof requires reliable findings from a number of high-quality studies, and we attempted to adhere to this in our survey. Thus, according to the evidence in our survey, we determined the following recommendations.

1) EMG-generated rehabilitation processes are relatively new and many features still require further development. In particular, systems for rehabilitation of some muscles in the human body require further development.

2) Noninvasive EMG, i.e., surface EMG, is much more comfortable for subjects.

3) The existing software and hardware technologies listed briefly are those that are useful if combined to build a new recovery mechanism.

4) It is highly recommended to consider cost during development of a prototype because patients generally intend to use low-cost systems to satisfy the multiple purposes.

5) Users prefer portable and home-oriented systems.

In summary, we suggest that EMG-assisted automatic rehabilitation systems should be noninvasive, incorporate online processes, be affordable, have a clear graphical user interface and be compact.

The scope of application of automatic rehabilitation systems for prompt recovery of muscle in the human body is great. Application to biceps tendonitis is one area that would be beneficial, and it is still a relatively undeveloped area in the rehabilitation field. Particularly, we will focus on a computerized rehabilitation system that makes use of EMG signal measurement using suitable software and hardware techniques because an automatic rehabilitation system using a computer has the potential to aid modern recovery techniques in addressing the destruction, disability and severe pain related to the damage in biceps tendonitis. Moreover, the real-time and on-line results of effective recovery practice are definitely better and quicker in the rehabilitation process compared with other traditional therapies or rehabilitation techniques. In summary, our future work will be on an automatic, noninvasive, real-time, portable and online system for this undeveloped muscle.

\section{REFERENCES}

1) Jaehoon J, Wonhak C, Yongchul K, et al.: Recognition of lower limb muscle emg patterns by using neural networks during the postural balance control. 3rd Kuala Lumpur Int'1 Conf on Biomedical Engineering, 2007, 15: 82-85.

2) Mohammaddan $S$, Komeda $T$ : Wire-driven mechanism for finger rehabilitation devices. IEEE int'l conf on Mechatronics and Automation, 2010, 10151018 .

3) Bansal D, Khan M, Salhan AK: Wireless transmission of EMG signal and analysis of its correlation with simultaneously acqired carotid pulse wave using dual channel system. 2nd IEEE Int Conf on eHealth, Telemedicine and Social Medicine, 2010, 125-129.

4) Reaz MB, Hussain MS, Mohd-Yasin F: Techniques of EMG signal analysis: detection, processing, classification and applications. Biol Proced Online, 2006, 8: 11-35.

5) Sasidhar S, Panda SK, Xu J: A real time control algorithm for a myoelectric glove for the rehabilitation of wrist and elbow of stroke patients. 8th IEEE Int'1 Conf on Control and Automation, 2010, 745.

6) Majdalawieh O, Gu JT, Bai GC: Biomedical signal processing and rehabilitation engineering: a review. IEEE Pacific Rim Conference on Communications, Computers and signal Processing, 2003, 2: 1004-1007.

7) Sangit S, Sanjib KP, Xu J: Design of a myoelectric glove for upper limb stroke rehabilitation. 3rd Int'1 Convention on Rehabilitation Engineering \& Assistive Technology, 2009.

8) Mulas M, Michele F, Giuseppina G: An EMG controlled exoskeleton for hand rehabilitation. 9th IEEE Int'1 Conf on Rehabilitation Robotics, 2005, 371-374.

9) Qingling L, Dongyan W, Zhijiang D, et al.: A novel rehabilitation system for upper limbs. 27th IEEE-EMBS Annual Int'l Conf of the Engineering in Medicine and Biology Society, 2005, 6840-6843.

10) Kiguchi K, Esaki R, Tsuruta T, et al.: An exoskeleton system for elbow joint motion rehabilitation. IEEE/ASME Int'l Conf on Advanced Intelligent Mechatronics, 2003, 2: 1228-1233.

11) Andreasen DS, Allen SK, Backus D A: Exoskeleton with EMG based active assistance for rehabilitation. 9th IEEE Int'1 Conf on Rehabilitation Robotics, 2005, 333-336

12) Son JS, Kim JY, Hwang SJ, et al.: The Development of an EMG-based Upper Extremity Rehabilitation Training System for Hemiplegic Patients. 13th Int'1 Conf on Biomedical Engineering,2009, 23: 1977-1979.

13) Chih-Fu W, Jeih-Jang L: PC-Based Rehabilitation System with Biofeedback. Conf. on Ergonomics and Health Aspects of Work with Computers. Springer Link, 2009, 5624: 204-211.

14) Steinisch M, Guarnieri BM, Haueisen J, et al.: Virtual reality and robotics for neuro-motor rehabilitation of ischemic stroke patients. World Congress on Medical Physics and Biomedical Engineering (IFMBE), Springer Link, 2009, 25: 61-63.

15) Homma K., Fukuda O, Sugawara J, et al.: A wire-driven leg rehabilitation system: development of a 4-DOF experimental system. IEEE Int'1 Conf on Advanced Intelligent Mechatronics, 2003, 2: 908-913.

16) Raichur A, Wihardjo G, Banerji S, et al.: A step towards home-based robotic rehabilitation: An interface circuit for EEG/SEMG actuated orthosis. IEEE/ ASME Int'l Conf on Advanced Intelligent Mechatronics, 2009, 1998-2003.

17) Xing S, Zhang X: EMG-driven computer game for post-stroke rehabilitation. IEEE Conference on Robotics Automation and Mechatronics, 2010, $32-36$.

18) Hokyoo L, Takaashi Y, Miyoshi T, et al.: Basic experiments of upper limb rehabilitation using haptic device system. 9th IEEE Int'1 Conf on Rehabilitation Robotics, 2005, 44-447.

19) Cano-Garcia JM, Gonzalez PE, Alarcon CV, et al.: A PDA-based portable wireless ECG monitor for medical personal area networks. Mediterranean Electro technical Conference, IEEE, 2006, 2: 713-716.

20) Michael H: Rehabilitation robotics from past to present -a historical perspective. Lecture Notes in Control and Information Sciences. Adv Rehabil Robot, 2004, 306: 25-44.

21) Jeong-Su H, Won-Kyung S, Jong-Sung K, et al.: New EMG Pattern Recognition based on Soft Computing Techniques and Its Application to Control of a Rehabilitation Robotic Arm. Fuzzy Logic Systems Institute, Japan, 2006. http: //flsi.cird.or.jp/ iizuka2000/PAPERS/D_3_3.PDF, (Accessed Nov. 10, 2010)

22) Xiao LH, Kai-yu T, Xiu JZ, et al.: A comparison between electromyography-driven robot and passive motion device on wrist rehabilitation for chronic stroke. J Neurorehabil Neural Repair, 2009, 23: 837-846. 